\title{
Numerical Analysis of Multicomponent Suspension Droplets in High-Velocity Flame Spray Process
}

\author{
Ebrahim Gozali, Mahrukh Mahrukh, Sai Gu, and Spyros Kamnis
}

(Submitted November 25, 2013; in revised form March 4, 2014)

\begin{abstract}
The liquid feedstock or suspension as a different mixture of liquid fuel ethanol and water is numerically studied in high-velocity suspension flame spray (HVSFS) process, and the results are compared for homogenous liquid feedstock of ethanol and water. The effects of mixture on droplet aerodynamic breakup, evaporation, combustion, and gas dynamics of HVSFS process are thoroughly investigated. The exact location where the particle heating is initiated (above the carrier liquid boiling point) can be controlled by increasing the water content in the mixture. In this way, the particle inflight time in the high-temperature gas regions can be adjusted avoiding adverse effects from surface chemical transformations. The mixture is modeled as a multicomponent droplet, and a convection/diffusion model, which takes into account the convective flow of evaporating material from droplet surface, is used to simulate the suspension evaporation. The model consists of several sub-models that include premixed combustion of propane-oxygen, non-premixed ethanol-oxygen combustion, modeling of multicomponent droplet breakup and evaporation, as well as heat and mass transfer between liquid droplets and gas phase.
\end{abstract}

Keywords HVSFS, multicomponent droplet, suspension, thermal spray process

\section{Introduction}

High-velocity suspension flame spray (HVSFS) process has been successfully developed to deposit very thin and dense coatings with excellent wear and corrosion resistance properties (Ref 1-5). In the HVSFS process, a suspension, instead of the conventional powder feedstock, is injected into the high-pressure and high-temperature combustion chamber where liquid droplets immediately undergo severe fragmentation and evaporation. After complete evaporation of the carrier droplets, individual micron- or nano-sized powder particles and/or micrometric agglomerates are released to the gas stream. The inflight particles are then heated, accelerated, and deposited on a substrate. These particles or agglomerates are much smaller compared to the conventional dry powder feedstock for HVOF or plasma spraying; hence, a smaller lamella size is gained $(\operatorname{Ref} 6,7)$.

The use of liquid suspension, which is a heterogeneous mixture containing solid particles and a solution or solvent (water, ethanol, or isopropanol), enables processing nanosized particles and fabricating nanostructured coatings in HVSFS and Suspension Plasma Spray (SPS) processes. Similarly, Solution Precursor Plasma Spray (SPPS) uses

Ebrahim Gozali and Spyros Kamnis, Xi'an Jiaotong-Liverpool University, Suzhou, China; and Mahrukh Mahrukh and Sai Gu, Cranfield University, Bedford, UK. Contact e-mails: spyros. kamnis@xjtlu.edu.cn and s_kamnis@hotmail.com. precursor feedstock where the nanoparticles that form the coating are synthesized in the plasma flow (Ref 7-10). The process characteristics, the microstructure, and phase composition of the coatings are significantly influenced by the liquid phase of the suspension or solution which can be homogeneous or a mixture solvent. Depending on the desired application, different types of solvent or mixture ratio are used. Solvent mixtures are recently employed in most of the HVSFS experiments mainly for the effective control of the degree of melting of nanoparticles or agglomerates and for modifying the physical properties of the solvent in order to achieve application-specific coatings (Ref 1-3). Ethanol, isopropanol, water, and their mixture are the most commonly used solvents.

Only few research groups have systematically studied the effects of suspension or solution composition on the processes and the microstructural properties of the coatings (Ref 1, 6, 11, 12). These experimental studies are largely focused on the effects of powder size distribution and type of solvent on nanostructured coatings. Most of these works investigate the effects of suspension or solution composition on the final outcome of the coatings and the process. The underlying physics is not elaborated due to the experimental limitations. None of these studies examined the effects of solvent mixture ratio on the process and microstructure of the coatings, for example, how the solvent composition influences the gas dynamics of the HVSFS process or at what extent suspension fragmentation and evaporation will be altered with different ratios of solvent mixture in the liquid phase. In all techniques, the solvent breakup and evaporation are the initial steps for the droplets to undergo further physical and chemical transformations. Hence, understanding the liquid phase (homogenous and mixture solvent) breakup, evaporation, 
combustion, and its effects on gas dynamics can further improve the process and coating structure. Moreover, no numerical investigation has been conducted on this matter. Besides, being devoted to many scientific activities regarding SPS and SPPS, HVSFS has been investigated by a few research groups and their works (Ref 13,14) are analyzed and complemented in our previous work (Ref 17).

The present numerical research, therefore, aims to analyze the effects of solvent type and solvent composition with different mixing ratios on the liquid droplet fragmentation, evaporation, combustion, and HVSFS gas dynamics. In this study, the solvent mixture is treated as a multicomponent droplet of ethanol and water with various ratios. It should be noted that modeling solvent as a multicomponent droplet is not yet addressed in the thermal spray literature. This work aims to bridge this gap and to provide information that help to depict the mixture solvent behavior in the HVSFS process. For this, a convection/diffusion model is employed to simulate multicomponent droplet evaporation which considers the convective flow of evaporating material from droplet surface (Stefan Flow). The model consists of several submodels that include modeling HVSFS flame jet turbulence by taking into account the compressibility effects, premixed combustion of propane-oxygen, non-premixed combustion of ethanol-oxygen, modeling aerodynamic one- and multicomponent droplet breakup, evaporation, and heat and mass transfer between liquid and gas phases, at the example of an industrial DJ2700 torch (Sulzer-Metco, Wohlen, Switzerland). This study is based on and continues the numerical analysis of the conventional HVOF thermal spray process as described in author's earlier work (Ref 15-17).

Extensive validation of the combustion, discrete phase, and flow model has been performed in earlier studies and, therefore, for brevity is not repeated here. The employed turbulent, combustion, and spray models have been vigorously tested against experimental data, respectively, in the open literature and have demonstrated accurate predictions (Ref 15-20). Thorough validation of the developed discrete phase breakup sub-model employed in this study can be found in Ref 20, 21. Here, the multicomponent droplets are ethanol and water mixture; different mass fractions of ethanol and water are used. The HVOF gun geometry used here is DJ2700 torch (Sulzer-Metco, Wohlen, Switzerland). The operating parameters along with the schematic representation of the computational domain are shown in Table 1 and Fig. 1, respectively. The droplets are injected into the combustion chamber with mass flow rate $0.0001 \mathrm{Kg} / \mathrm{s}$ and with an initial temperature $300 \mathrm{~K}$. This mass flow rate has been selected according to the results in the previous study (Ref 17). It was assumed that during atomization, an initial uniform droplet diameter of $300 \mu \mathrm{m}$ is generated (diameter of the injection nozzle).

\section{Numerical Scheme and Governing Equations}

The governing equation of the gas-phase flow is provided in Ref $15,16,20,22$, and 23 and thus is briefly
Table 1 Geometric parameters and the working conditions

\begin{tabular}{|c|c|c|}
\hline \multicolumn{3}{|l|}{ Geometric parameter $(\mathrm{m})$} \\
\hline $\begin{array}{l}\text { Combustion chamber } \\
\text { length }\end{array}$ & 0.0238 & \\
\hline $\begin{array}{l}\text { Combustion chamber } \\
\text { diameter }\end{array}$ & 0.0182 & \\
\hline Nozzle throat diameter & 0.0084 & \\
\hline Barrel length & 0.01243 & \\
\hline Barrel exit diameter & 0.0662 & \\
\hline \multicolumn{3}{|l|}{ Working conditions } \\
\hline Fuel flow rate & $0.004 \mathrm{~kg} / \mathrm{s}$ & Temp.: $300 \mathrm{~K}$ \\
\hline Oxygen flow rate & $0.014 \mathrm{~kg} / \mathrm{s}$ & Temp.: $300 \mathrm{~K}$ \\
\hline Air flow rate & $0.002 \mathrm{~kg} / \mathrm{s}$ & Temp.: $300 \mathrm{~K}$ \\
\hline Atm. pressure, temp. & $101325 \mathrm{~Pa}, 300 \mathrm{~K}$ & \\
\hline Wall boundary temp. & $\begin{array}{l}\text { Temp.: } 300 \mathrm{~K}, \\
\text { Non-slip }\end{array}$ & \\
\hline $\begin{array}{l}\text { Droplet diameter } \\
\text { and initial temp. }\end{array}$ & $300 \mu \mathrm{m}, 300 \mathrm{~K}$ & \\
\hline $\begin{array}{l}\text { Droplet flow rate } \\
\text { and initial velocity }\end{array}$ & $0.0001 \mathrm{~kg} / \mathrm{s}, 30 \mathrm{~m} / \mathrm{s}$ & \\
\hline
\end{tabular}
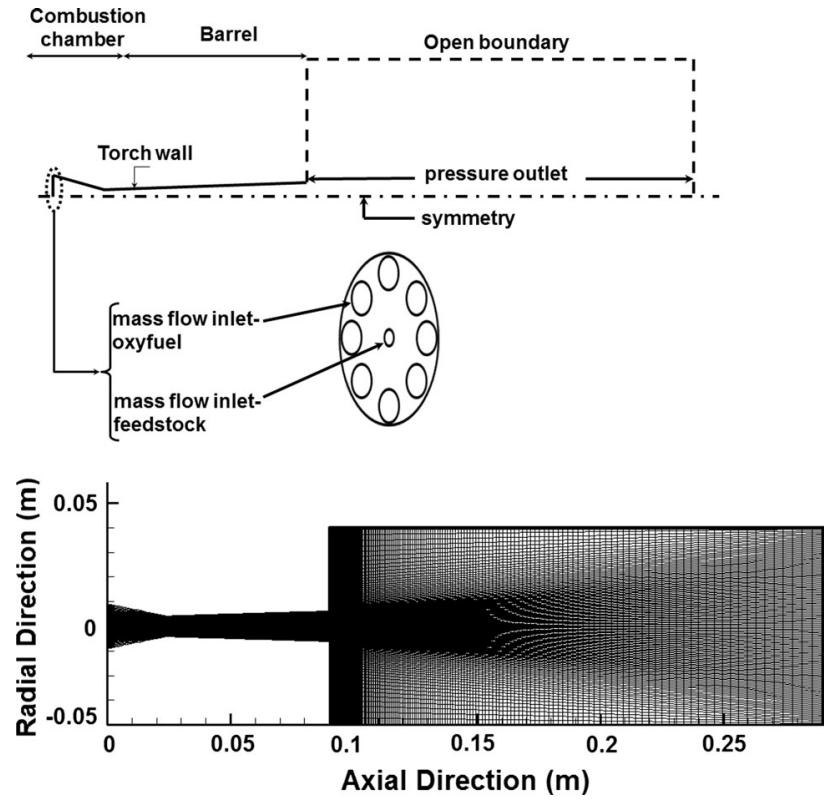

Fig. 1 Schematic diagram of the axisymmetric computational domain along with boundary conditions and mesh design of DJ2700 gun

described here. The first part of model simulates the temperature and velocity fields of an HVSFS flame jet. The realizable $\mathrm{k}-\varepsilon$ model is used for modeling the turbulence in the jet, including compressibility effects. Both premixed (oxygen-propane) and non-premixed (oxygenethanol) are solved by eddy dissipation model with hyperstoichiometric oxygen mass fraction. Having solved the gas phase, the injection of liquid ethanol droplets into the high-pressure combustion chamber is modeled by a discrete phase model. Since the Ohnesorge number remains very below $0.1(\mathrm{Oh} \ll 0.1)$ in the computational domain, the main parameter related to break-up physics is the Weber number. The secondary breakup of droplets to 
smaller ones is modeled by Taylor Analysis Breakup (TAB) model. This model is well adapted to the conditions of spraying as it is validated in the previous studies (Ref 20). The single- and multicomponent droplet heat and mass transfer with continuous phase is modeled based on the "laws" described in the following section.

\section{Model Development}

\subsection{Single Droplet Heat Up and Vaporization}

The homogenous droplet heat and mass transfer with continuous phase is modeled based on three laws. At each tracking time, the relevant law is applied based on the time- and space-dependent droplet conditions. Details of the laws, equations of motion, and droplet secondary breakup are described elsewhere (Ref 17, 20, 22, 23). However, a modification has been done to the second law of the vaporization, which takes into account the effects of the convective flow of the evaporating material from the droplet surface to the bulk phase. The law 2 or convection/ diffusion-controlled model has been adopted following the work of Miller et al. (Ref 24) and Sazhin (Ref 25):

$\frac{d m_{p}}{d t}=A_{p} k_{c} \rho_{\infty} \ln \left(1+\mathrm{B}_{m}\right)$,

where $m_{p}$ and $A_{p}$ are droplet mass and droplet surface area, $\rho_{\infty}$ is density of bulk gas, $k_{c}$ is mass transfer coefficient, and $B_{m}$ is the Spalding number given by:

$B_{m}=\frac{\left(Y_{i, s}-\mathrm{Y}_{i, \infty}\right)}{1-Y_{i, s}}$,

where $Y_{i, s}$ is the vapor mass fraction at the droplet surface, $Y_{i, \infty}$ is the vapor mass fraction in bulk gas, and $k_{c}$ is calculated from the Sherwood number correlation (Ref 26, 27) as:

$\mathrm{Sh}_{\mathrm{AB}}=\frac{k_{c, i} d_{p}}{D_{i, m}}\left(2+0.6 R e_{d}^{0.5} \mathrm{Sc}^{1 / 3}\right)$,

where $D_{i, m}$ is the diffusion coefficient of vapor in the bulk phase, $\left(\mathrm{m}^{2} / \mathrm{s}\right)$; Sc is the Schmidt number, $\mu / \rho D_{i, m} ; d_{p}$ is the droplet diamelter ${ }_{p-}(\mathrm{m}) ; R e_{d}$ is the relative Reynolds number, $R e_{d}=\frac{\mid \mu p^{\prime}}{\mu}$.

Here, $\overrightarrow{\mathrm{u}}$ is the fluid phase velocity, $\overrightarrow{\mathrm{u}}_{p}$ is the particle velocity, $\mu$ is the molecular viscosity of the fluid, and $\rho$ is the fluid density.

\subsection{Multicomponent Droplet Heat Up and Vaporization}

A multicomponent particle is a droplet particle containing a mixture of several components or species (ethanol and water in this study). The conservation equations of all components, the energy equation, and vapor-liquidequilibrium at the multicomponent particle surface form a coupled system of differential equations. A multicomponent law is developed for such systems described in this section.
The volume-weighted-mixing-law is used to define the particle mixture density. The particle mass " $m$ " is the sum of the masses of the components:

$m_{\text {mix }}=\sum_{i} m_{i}$.

The density of the particle $\rho_{\text {mix }}$ is volume-averaged:

$\rho_{\text {mix }}=\left(\sum_{i} \frac{m_{i}}{m \rho_{i}}\right)^{-1}$.

The other properties of multicomponent droplet such as viscosity, specific heat, and surface tension are defined as mass-weighted-mixing-law, which is computed based on a simple mass fraction average of pure species properties:

$\emptyset_{\text {mix }}=\sum_{i} Y_{i} \emptyset_{i}$

where $Y_{i}$ is mass fraction of component $i$. The complete droplet properties are listed in Table 2. Saturation vapor pressure and diffusion coefficient of one-component droplets are input as function of temperature. A filmaveraged temperature is defined based on droplet- and gas-phase temperatures for accurately computing diffusion coefficient of single-component droplets:

$T_{f}=T_{p}+a\left(T_{\infty}-T_{p}\right)$,

where $T_{p}, T_{\infty}$, and $a$ are droplet, gaseous temperatures, and average coefficient, respectively.

The evaporation rate of multicomponent droplet is calculated as the sum of the vaporization rates of the individual components and the vaporization rate of component $i$ and is given by:

$\frac{d m_{i}}{d t}=A_{p} k_{c, i} \rho_{\infty} \ln \left(1+B_{m, i}\right)$,

where $m_{i}$ is the mass of component $i$ in droplet $(\mathrm{kg}), k_{c, i}$ is the mass transfer coefficient of component $i(\mathrm{~m} / \mathrm{s})$ given by Eq $3, B_{m, i}$ is the Spalding mass number for species $i$ and is given by Eq 2 .

When the total vapor pressure at the droplet surface exceeds the cell pressure, the multicomponent droplet is in the boiling regime and boiling rate Eq 6 is applied. The total vapor pressure is computed as $P_{t}=\sum P_{i}$ where $P_{i}$ is the partial pressure of component " $i$."

$\frac{d m_{i}}{d t}=x_{i} \frac{\pi k_{\infty} d_{p}}{C_{p \infty}}\left(2+0.6 R e_{\mathrm{d}}^{0.5} \operatorname{Pr}\right) \ln \left(1+B_{T, i}\right)$

where $x_{i}$ is the volume fraction of component " $i$ " in the droplet, $k_{\infty}$ is the thermal conductivity of the continuous phase, $C_{p \infty}$ is the specific heat of the continuous phase, $B_{T, i}$ is the Spalding heat transfer number for component " $i, " B_{T, i}=\frac{C_{p \infty}\left(T_{\infty}-T_{d}\right)}{h_{\text {vap }, i}}$.

The equation for the multicomponent droplet temperature $T$ contains terms for convective heating and evaporation and is cast similarly to the one-component droplet energy equation. The energy equation for the multicomponent particle is written as follows: 
Table 2 Properties are taken from Perry's Chemical Engineering Handbook (Ref 28) and curve-fitted in their temperature range

\begin{tabular}{|c|c|c|c|}
\hline Properties & Water (liquid) & Ethanol (liquid) & Mixture \\
\hline Density $\left(\mathrm{Kg} / \mathrm{m}^{3}\right)$ & 998.2 & 790 & Volume-weighted-mixing-law \\
\hline Specific heat $(\mathrm{J} / \mathrm{Kg} \mathrm{K})$ & 4182 & 2470 & Mass-weighted-mixing-law \\
\hline Viscosity $(\mathrm{Kg} / \mathrm{m} \mathrm{s})$ & 0.001003 & 0.0012 & Mass-weighted-mixing-law \\
\hline Latent heat $(\mathrm{J} / \mathrm{Kg})$ & 2263073 & 855237 & $\ldots$ \\
\hline Vaporization temperature $(\mathrm{K})$ & 284 & 271 & $\ldots$ \\
\hline Boiling point $(\mathrm{K})$ & 373 & 351 & $\ldots$ \\
\hline Binary diffusivity $\left(\mathrm{m}^{2} / \mathrm{s}\right)$ & Film-averaged & Film-averaged & $\ldots$ \\
\hline Saturation vapor pressure (pa) & Piecewise-linear & Piecewise-linear & $\ldots$ \\
\hline Surface tension $(\mathrm{n} / \mathrm{m})$ & 0.0719404 & 0.022348 & Mass-weighted-mixing-law \\
\hline Vaporization model & $\ldots$ & $\ldots$ & Convection/diffusion-controlled \\
\hline Vapor-particle-equilibrium & $\ldots$ & $\ldots$ & Raoult's-law \\
\hline
\end{tabular}

$m_{p} c_{p} \frac{d T}{d t}=h A_{d}\left(T_{\infty}-T_{d}\right)+\sum_{i} \frac{d m_{i}}{d t}\left(h_{\mathrm{vap}, i}\right)$

where $d m_{i} / d t$ is computed from $\mathrm{Eq} 8$ or 9 and $h_{\mathrm{vap}, i}$ is the latent heat of vaporization for component " $i$."

The heat transfer coefficient $h$ is computed as:

$\mathrm{Nu}=\frac{h d_{p}}{k_{\infty}}=\frac{\ln \left(1+B_{T}\right)}{B_{T}}\left(2+0.6 \operatorname{Re}_{\mathrm{d}}^{0.5} \operatorname{Pr}^{1 / 3}\right)$.

The Prandtl number of continuous phase is given by $\operatorname{Pr}=\frac{c_{p} \mu}{k_{\infty}}$.

$B_{T}$ is the Spalding heat transfer number and is assumed to be equal to the Spalding mass transfer $B_{m}$ calculated from $\mathrm{Eq}$ 8:

$B_{T}=B_{m, i}$.

Finally, the correlation between the vapor concentration of a species $C_{i, s}$ over the droplet surface and its mole fraction in the condensed phase $x_{i}^{L}$ is described by Raoult's law (see Eq 13):

$C_{i, s}=\frac{p_{i}}{R T}=\frac{x_{i}^{L} P_{\mathrm{sat}, i}}{R T}$

\section{Results and Discussion}

With the assumption that nanoparticle loading is very low, the suspension is treated as homogenous droplet particles either in the form of single- or multicomponent droplets, representing pure and mixture solvent, respectively. Since the results of gas-phase modeling and parameters controlling the HVSFS process such as droplet mass flow rate, droplet size, and initial velocity are extensively described in the previous studies (Ref 15-17), only illustration of solvent fragmentation, evaporation, and cooling effect is adequate to highlight the effects of solvent type or mixture ratio on the HVSFS process. Therefore, those results will not be further analyzed here. It should be noted that mixture of solvent with different ratios is commonly used in the HVSFS process and their ratio in practice is found by performing costly trial and error experiments. The mixture ratios, in this study, are selected according to the commonly used ratios in experimental studies in order to illustrate their impact on the process. Without droplet case in the text and graphs refers to the case in which no droplets are injected into the gun and denotes the HVOF gas dynamics. Droplets are injected through gas carrier tube inlet at the center of the $\mathrm{O} /$ $\mathrm{F}$ mixer, and it is surface injection.

\subsection{Effects of Solvent Mixture Ratio on Its Vaporization}

Different ratios of ethanol and water mixture (multicomponent droplet) are injected into the DJ2700 gun, and their trajectories are numerically studied. Among them, four ratios are selected, namely: pure ethanol, $90 \%$ ethanol- $10 \%$ water, $50 \%$ ethanol-50 \% water, and pure water. Both single- and multicomponent droplet mass flow rates, diameters, and initial velocities are selected to be $0.1 \mathrm{~g} / \mathrm{s}$, $300 \mu \mathrm{m}$, and $30 \mathrm{~m} / \mathrm{s}$, respectively. These initial injection parameters are selected based on the previous parametric study (Ref 17). The initial droplet temperature is assumed to be $300 \mathrm{~K}$. Figure 2 shows the rate of evaporation of these mixtures in HVSFS process along the axis of the computational domain. It is evidently shown that maximum evaporation occurs inside the combustion chamber for the cases with high ethanol content in the solvent. All droplets evaporate well before the gun exit. In contrast, for multicomponent droplets with high percentage of water (more than $50 \%$ ), the evaporation is significantly delayed and takes place in all internal regions of the gun including the external jet region in some cases. The longest distance of complete evaporation in free jet region is observed for pure water ( $57 \mathrm{~mm}$ away from gun's barrel exit). Monitoring the vaporization rate of droplets inside the nozzle and the free jet region (Fig. 3), it can be realized that adding small quantities of water (almost $10 \%$ ) to ethanol solvent does not affect considerably the evaporation rate. In this case, all liquid droplets evaporate completely before the gun exit. However, the area of maximum evaporation shifts to the barrel and the final location of evaporation moves to the free jet region when the solvent is pure water. It should be noted that droplets are mainly concentrated on the gun axis due to its injection structure located at the center of the O/F mixer. For this reason, the centerline axis is chosen for presenting the 
main findings of this study. Droplets experience severe fragmentation in the middle of the combustion chamber. The high gas temperature, velocity, and turbulence intensity are the main reasons for the resulting oscillating behavior in droplet evaporation rate as illustrated in Fig. 2 and 3 .

A physical property that has a significant influence on the vaporization rate is the solvent boiling point. Figure 4 shows the variation of the boiling temperature of these mixtures along the centerline. A comparison between Fig. 4 and previous ones (Fig. 2 and 3) reveals that the

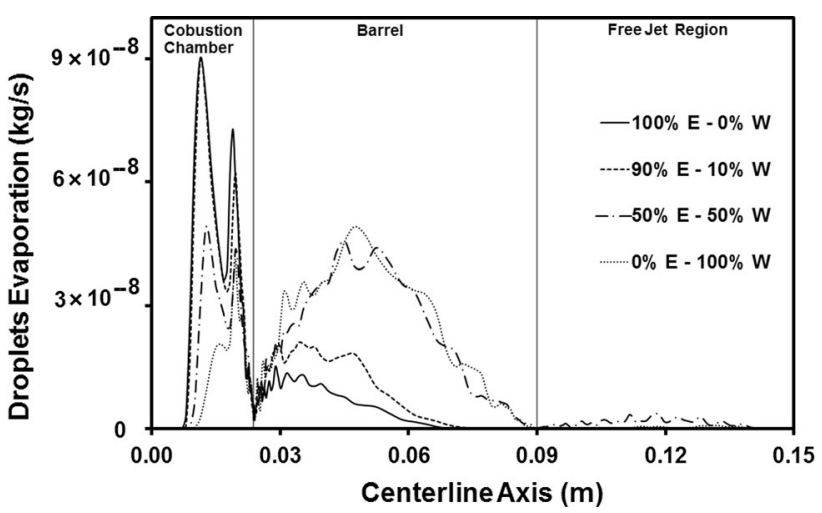

Fig. 2 Rate of evaporation of droplets carrying four different percentages of ethanol-water in solvent along the centerline lower the solvent boiling temperature, the higher the vaporization rate. In fact, solvent with high content of ethanol possesses lower boiling temperature and requires less heat for full evaporation, whereas increasing the mass fraction of water in the solvent leads to rise in boiling temperature and in turn the evaporation rate becomes smaller. Also, it should be noted that the boiling temperature in all cases varies inside the nozzle due to the changes in the pressure. The ethanol boiling temperature is $351 \mathrm{~K}$ in atmospheric pressure while it is approximately $400 \mathrm{~K}$ inside the combustion chamber that operates under high pressure of almost 4 bar and decreases along the centerline as pressure is falling.

These results are consistent with experimental studies in the literature (Ref $6,11,12)$. In the suspension plasma spray, which is a process similar to the HVSFS, Fauchais et al. (Ref 6) contacted experimental studies on the effects of ethanol and water solvent on the zirconia splat formation. They found under the same plasma and processing conditions, water droplets evaporate later than ethanol droplets and the zirconia particles contained in ethanol were melted while those in water were partially melted. In solution precursor plasma spray, which is again a similar process to the HVSFS, Chen et al. (Ref 12) studied experimentally the influence of solvent type on splat formation and coating microstructure. They found that droplets with a high surface tension and high boiling point undergo incomplete evaporation in the plasma jet resulting in porous coatings. In contrast, droplets with low

\section{Evaporation (kg/s)}

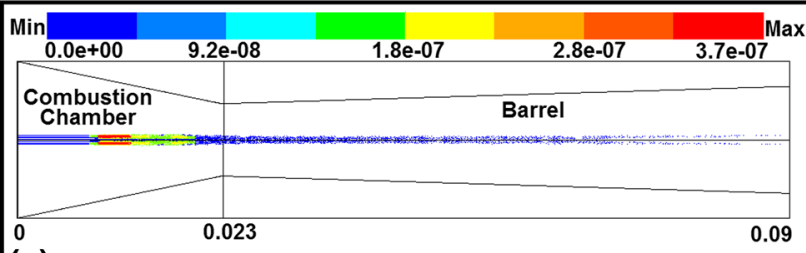

(a)

Axial Direction $(\mathrm{m})$



(b)
Axial Direction $(\mathrm{m})$



(c)

Axial Direction $(\mathrm{m})$

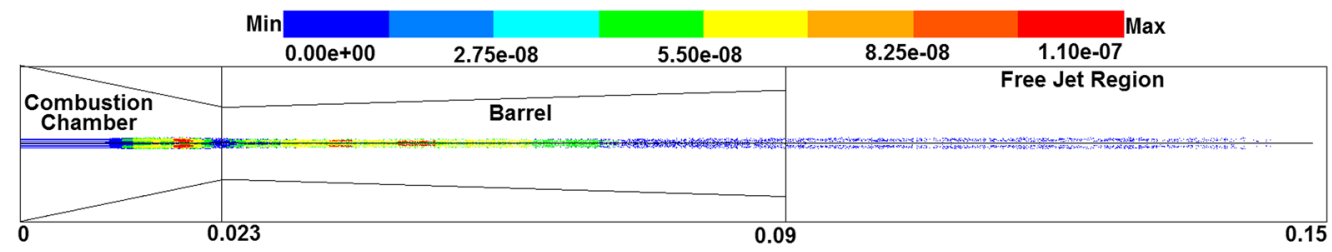

(d)

Axial Direction $(\mathrm{m})$

Fig. 3 Rate of evaporation of droplets carrying (a) 100\% E-0\% W, (b) $90 \%$ E- $10 \%$ W, (c) $50 \%$ E-50\% W, and (d) $0 \%$ E- $100 \%$ W, ethanol-water in solvent inside the nozzle 
surface tension and low boiling point experience rapid solvent evaporation followed by fully molten splat microstructure and high density coatings. The numerical results in this study are fully aligned with major experimental outcomes in literature. Organic solvent (ethanol) or solvent mixture with low percentage of water undergoes fast evaporation and subsequent early release of nanoparticles. The exact location where the particle heating is initiated (above the carrier liquid boiling point) can be controlled by increasing the water content of the mixture. In this way, the particle inflight time in the hightemperature gas regions can be adjusted for controlling the undesirable surface chemical transformations. Numerical modeling is the only direct method which can

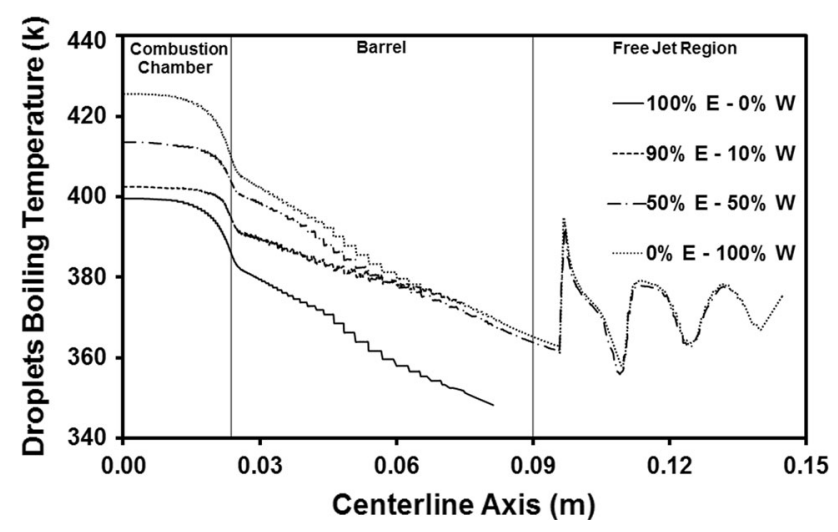

Fig. 4 Boiling temperature of droplets carrying different percentages of ethanol-water in solvent along the centerline
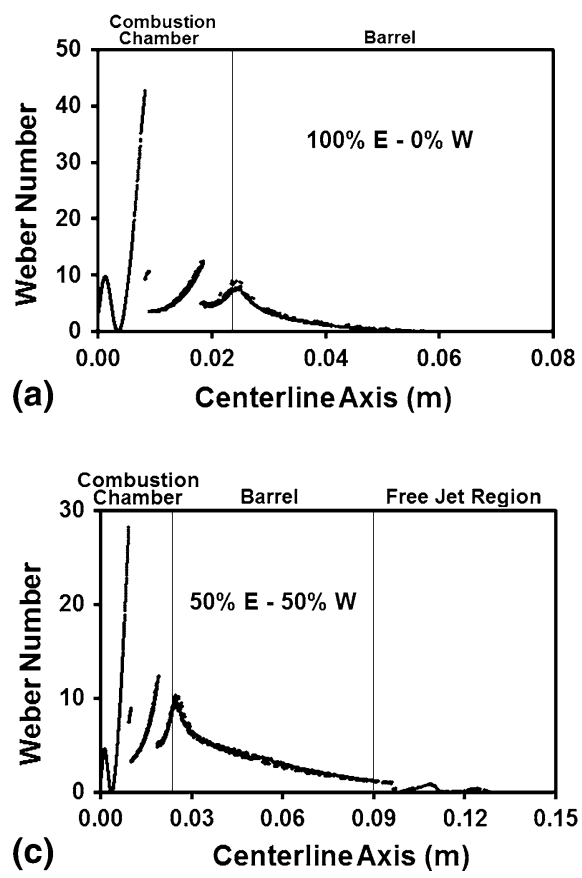

provide such information overcoming the technical constrains imposed by the experiments.

\subsection{Effects of Solvent Mixture Ratio on Droplet Fragmentation}

Droplet fragmentation is another important phenomenon in the HVSFS process which can be influenced by the solvent type and solvent mixture ratio. As long as the Ohnesorge number remains well below 0.1 in the computational domain, viscous forces are negligible and aerodynamic and surface tension forces are the only dominant parameters affecting the droplet fragmentation. The TAB model is selected, because the Weber number remains below 100 in the computational domain. Figure 5 illustrates the Weber number of droplets injected into the DJ2700 gun under various ethanol-water ratios in the solvent along the centerline. Maximum Weber number of about 44 is observed for the solvent with pure ethanol (Fig. 5a), and the maximum Weber number decreases by rising the water mass fraction in the solvent (Fig. 5b and c). Weber number reaches the lowest value of almost 22 (Fig. 5d) when the solvent is pure water. The reason is that the value of surface tension for ethanol $\left(\sigma_{\text {eth }}=\right.$ $\left.22 \times 10^{-3} \mathrm{~N} / \mathrm{m}\right)$ is three times less than that of water $\left(\sigma_{\mathrm{W}}=72 \times 10^{-3} \mathrm{~N} / \mathrm{m}\right)$. Hence, solvent with high percentage of ethanol has higher Weber number. Furthermore, the Weber number fluctuation shown in Fig. 5 is attributed to the fast developing relative velocity between droplets and gas phase. The increased inertial to surface tension forces result in successive droplet breaking up inside the combustion chamber.
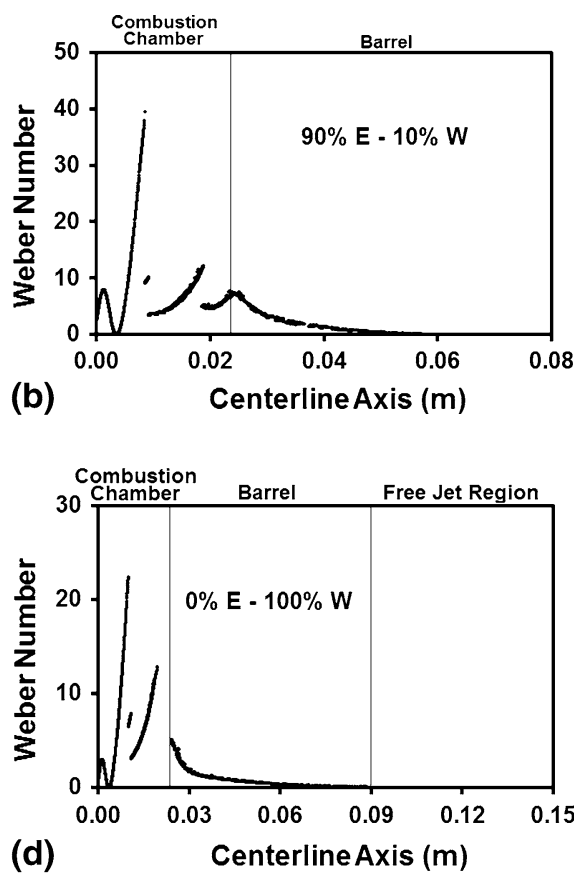

Fig. 5 Weber number of droplets carrying (a) 100\% E-0\% W, (b) $90 \%$ E-10\% W, (c) $50 \%$ E-50\% W, and (d) $0 \%$ E- $100 \%$ W, ethanolwater in solvent along the centerline 

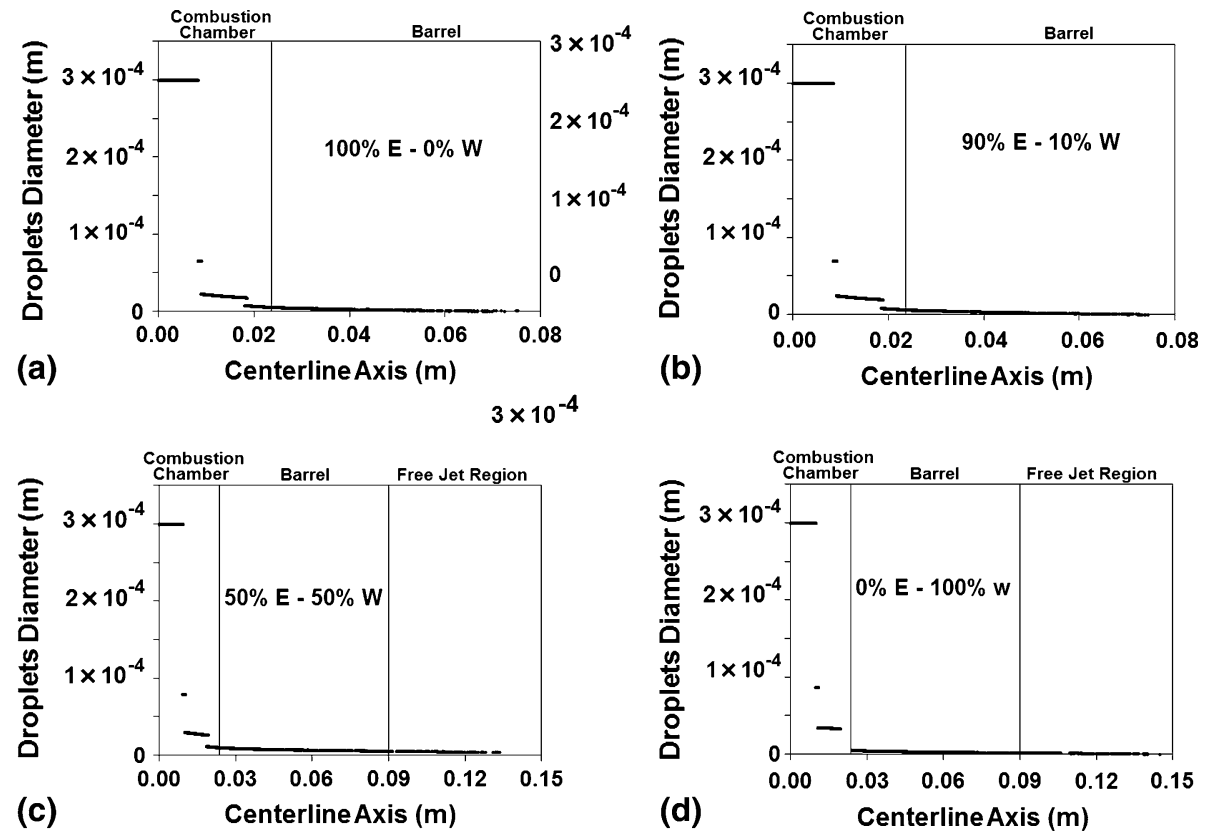

Fig. 6 Variation of droplet diameter containing (a) 100\% E- $0 \% \mathrm{~W}$, (b) $90 \%$ E- $10 \% \mathrm{~W}$, (c) $50 \%$ E-50\% W, and (d) $0 \%$ E- $100 \%$ W, ratios of ethanol and water in solvent along the centerline

In all cases, the value of Weber number stays well above 14 inside the combustion chamber, which indicates relatively high fragmentation. This can be clearly seen in Fig. 6 and 7 that display the reduction of droplet diameter with varying ethanol-water ratios in the solvent along the axis. For all cases, droplets undergo severe fragmentation at two subsequent locations inside the combustion chamber. First fragmentation occurs in the middle of combustion chamber causing a sharp decrease in the droplet size from $300 \mu \mathrm{m}$ to $66,71,82$, and $88 \mu \mathrm{m}$, for $100 \% \mathrm{E}-0 \% \mathrm{~W}$, $90 \% \mathrm{E}-10 \% \mathrm{~W}, 50 \% \mathrm{E}-50 \% \mathrm{~W}$, and $0 \% \mathrm{E}-100 \% \mathrm{~W}$ cases, respectively. The second fragmentation occurs some distance away from the first location (shown in Fig. 7) and results in a considerable reduction of droplet diameter from 66 to 23,71 to 25,82 to 30 , and 88 to $35 \mu \mathrm{m}$. Then, the droplets leave the combustion chamber with 5, 5, 9, and $13 \mu \mathrm{m}$, for the abovementioned cases, respectively. The pick reduction of droplet diameter is attributed to the corresponding maximum Weber number inside the combustion chamber for each case. However, having left the combustion chamber, it is evident that droplets experience much less effective breakup in the barrel and outside the gun. The reason is that the Weber number lies under 10 , while vaporization dominates the droplet size reduction process. In some cases, the escaping larger droplets experience late evaporation due to their high traveling speed meaning that their dwell time is low (Fig. $7 \mathrm{c}$ and d).

In summary, liquid droplets experience severe fragmentation two times inside the combustion chamber in the HVSFS gun owning to the large relative velocities. The intensity of the breakup depends mainly on the type of solvent and solvent mixture ratio: the lower the solvent surface tension, the more intense the breakup.

\subsection{Effects of Solvent Mixture Ratio on the HVSFS Gas Dynamics}

Four different ratios of ethanol and water mixture $(100 \% \mathrm{E}+0 \% \mathrm{~W}, 90 \% \mathrm{E}+10 \% \mathrm{~W}, 50 \% \mathrm{E}+50 \% \mathrm{~W}$, and $0 \% \mathrm{E}+100 \% \mathrm{~W})$ as solvent are selected and their evaporation and corresponding cooling on the HVSFS gas temperature and velocity are investigated, as illustrated in Fig. 8 and 9. It is clear from Fig. 8 that for all solvent compositions, the gas temperature drops to some extent along the axis. However, the cooling intensity depends on the type of solvent and solvent mixture ratio: combustible ethanol droplets have the lowest cooling effect on the gas temperature which mainly takes place inside the combustion chamber and moderately in the barrel. This means the evaporation is completed earlier and discharged nanoparticles have enough time to melt and leave the gun with high velocities. In contrast, adding a small amount of water into the solvent mixture results in highly reduced gas temperature both inside the combustion chamber and the barrel. The extreme gas cooling of approximately $1000 \mathrm{~K}$, mainly in the barrel, is reasonably observed for pure water solvent. This is due to the fact that water droplets are less sensitive to aerodynamic breakup compared to ethanol droplets. Gradual evaporation occurs along the nozzle and free jet region leading to gas-phase cooling. High cooling of the gas temperature can cause flame stretching which can trigger instabilities within the gun and eventually reduction of the gas velocity. The effects of solvent evaporation on the gas velocity can be seen in the Fig. 9. Similarly, the gas velocity is highly influenced by droplet evaporation and gas cooling as such the maximum reduction of about $250 \mathrm{~m} / \mathrm{s}$ in the barrel is 


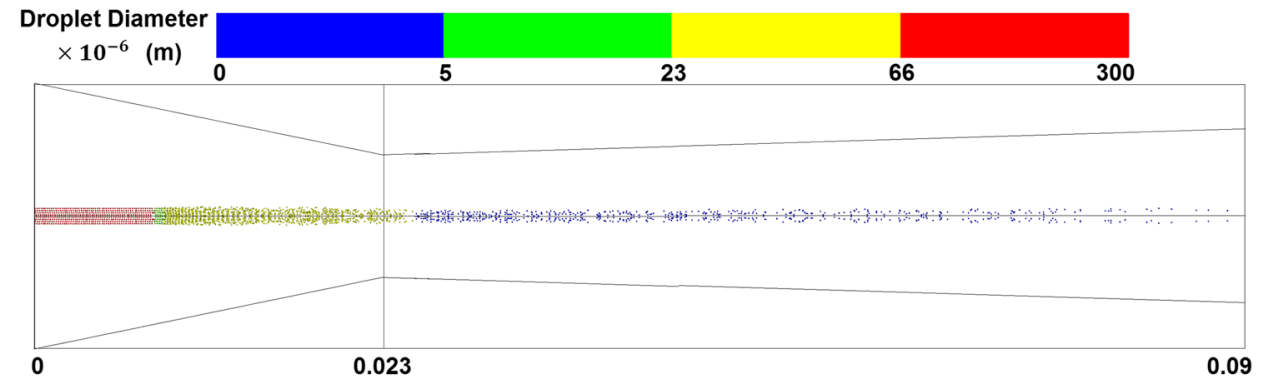

(a)

Axial Direction (m)

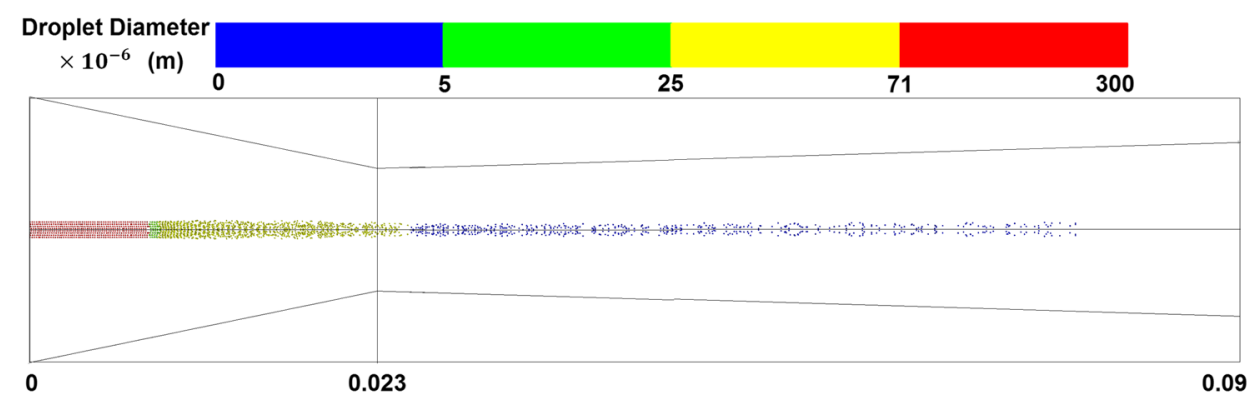

(b)

Axial Direction (m)
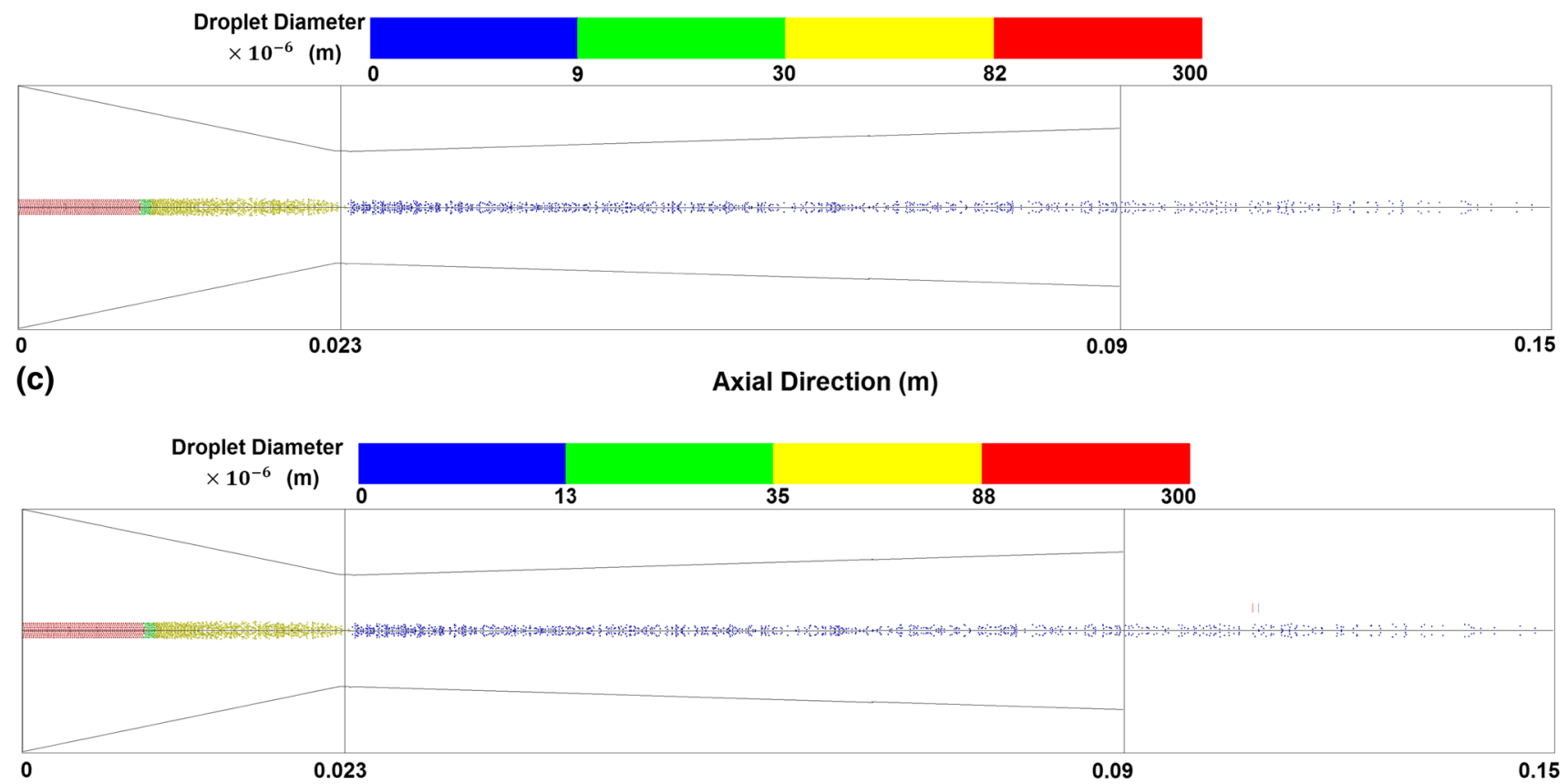

(d)

Axial Direction (m)

Fig. 7 Variation of droplet diameter containing (a) 100\% E- $0 \% \mathrm{~W}$, (b) $90 \%$ E-10\% W, (c) 50\% E-50\% W, and (d) $0 \%$ E- $100 \%$ W, ratios of ethanol and water in solvent inside the nozzle

observed for the case with pure water, which corresponds to the maximum gas cooling. The influence of the solvent composition in the aerodynamic and thermal performance of the gun opens a new window for active flow control of the HVOF process by adjusting the solvent mixture ratio to the desired levels. Overall, the results suggest that any liquid solvent considerably cools down the gas temperature and influences the gas velocity. However, the amount of cooling, location of the cooling, and consequent reduction in the gas velocity dent heavily on the type of solvent and solvent mixture ratio: organic solvent or mixture with high percentage of that has less effect on the gas dynamics, whereas aqueous solution has a higher impact on the gas temperature and velocity.

Another important quantitative parameter is the resulting gas Mach number. The coating particle velocity 


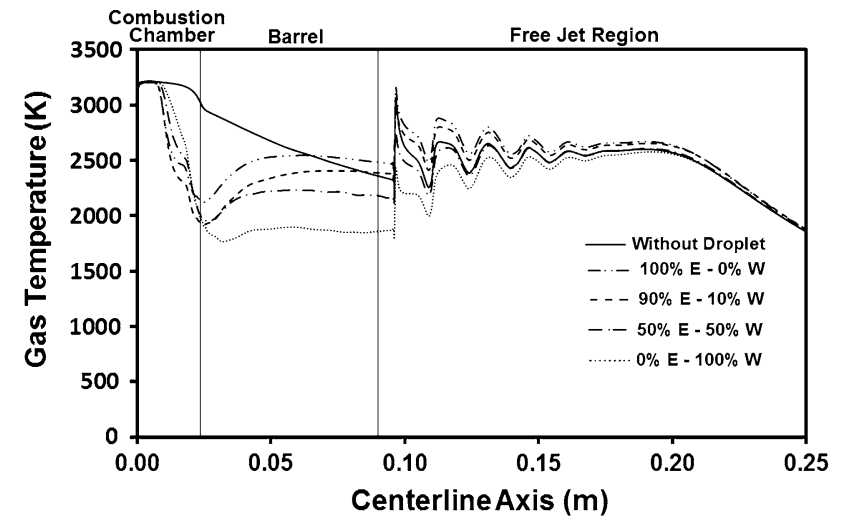

Fig. 8 Profile of gaseous temperature for without droplet case and cases with droplets carrying different percentages of ethanolwater in solvent along the centerline

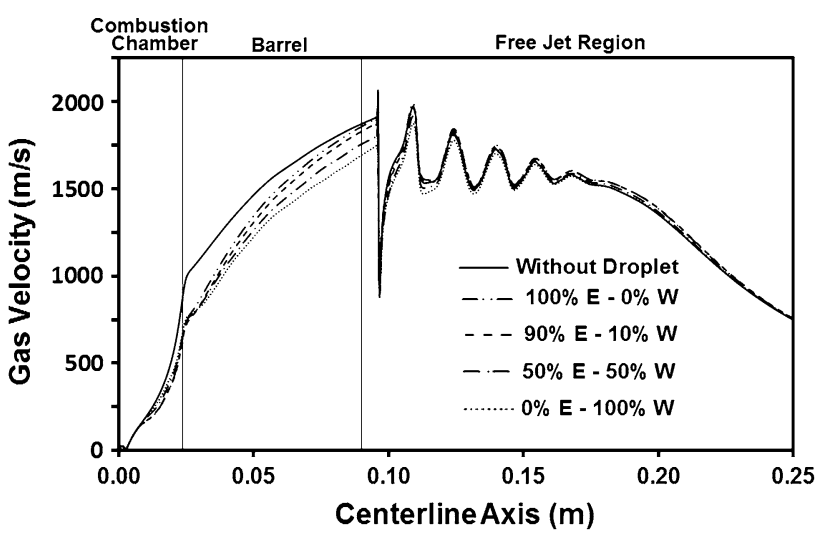

Fig. 9 Profile of gaseous velocity for without droplet case and cases with droplets carrying different percentages of ethanolwater in solvent along the centerline

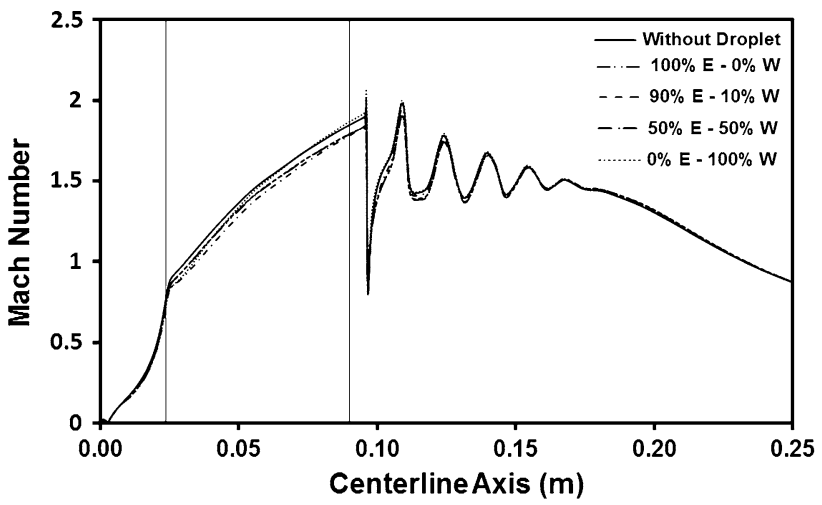

Fig. 10 Profile of gas Mach number for without droplet case and cases with droplets carrying different percentages of ethanolwater in solvent along the centerline

can be directly affected by the gas Mach number. Figure 10 shows the gas Mach number before and after injection along the centerline. The numerical results indicate that the gas Mach number after injection is almost identical to single-phase simulation especially near the throat, where density fluctuations develop a series of sock diamonds. This means that droplet injection either in the forms of single or multicomponent has no significant effect on the gas Mach number under the conditions described in this study.

It should be noted that in the original design of the DJ 2700 gun, the gas carrier tube is located at the center of the $\mathrm{O} / \mathrm{F}$ mixer surrounded by annular $\mathrm{O} / \mathrm{F}$ inlets. That means there is a recirculation zone close to the back wall at the injection area. For this reason, the particles start to spread out near the nozzle throat where the flame front converges toward the axis of the torch and interacts with the droplets. Moreover, it should be mentioned that the validity of these results stands only for uniform droplet diameter distribution injected into the HVSFS jet. In practice, droplets are injected in a spray cone with a range of droplet sizes. This, along with the velocity oscillations of the unsteady HVSFS jet, may create droplets anywhere in the domain from submicrons to tens of microns in diameter. Furthermore, these results reflect better the phenomena occurring when the droplet size is $300 \mu \mathrm{m}$, as smaller droplet may evaporate faster without severe fragmentation.

\section{Conclusion}

In this numerical investigation, three types of solvent in the HVSFS process were investigated, namely: pure ethanol, mixed ethanol and water, and pure water. The solvent fragmentation, evaporation, and HVSFS gas dynamics are methodically analyzed. The results of this work can be used as a reference for avoiding extraneous trial and error experimentations. It can assist in adjusting the spraying parameters for different powder materials, and it can provide a means of visualization of the phenomena taking place during liquid spray. The particle inflight heating can be effectively controlled by altering the solvent composition, while the temperature and velocity of the exhaust gases can be pitched at the appropriate level in the same way.

Organic solvent or mixture with high percentage of combustible species experiences rapid evaporation due to the lower boiling point, while solvent containing aqueous solution or mixture with high aqueous percentage undergoes slower evaporation. Since large relative velocities between liquid droplets and gas phase are developed in the combustion chamber, the aerodynamic breakup of particles is more pronounced. Pure solvent or multicomponent solvent droplets leave the combustion chamber with an average size of $5 \mu \mathrm{m}$ due to lower surface tension. Full evaporation is achieved before the gun exit. In contrast, those droplets with high surface tension pass through the convergent-divergent section with a diameter larger than $10 \mu \mathrm{m}$. When the relative liquid/gas velocity becomes smaller, the droplets evaporate and release the nanoparticles far from the gun exit.

The process of droplet evaporation and breakup has a significant influence on the HVSFS gas dynamics. In cases 
of multicomponent droplets of high percentage of organic solvent, less cooling is observed. The spontaneous temperature drop upon injection is effectively recovered after secondary (solvent/oxygen) combustion. Large disruption of the gas velocity is prevented mainly due to the limiting cooling effect which allows for high-pressure build-up in the combustion chamber.

\section{Acknowledgment}

The authors would like to acknowledge financial support for the research studentship from the School of Engineering in Xi'an Jiaotong-Liverpool University and the financial support by the UK Engineering and Physical Sciences Research Council (EPSRC) Project Grant: EP/ K027530/1.

\section{References}

1. G. Bolelli, V. Cannillo, R. Gadow, A. Killinger, L. Lusvarghi, J. Rauch, and M. Romagnoli, Effect of the Suspension Composition on the Microstructural Properties of High Velocity Suspension Flame Sprayed (HVSFS) $\mathrm{Al}_{2} \mathrm{O}_{3}$ Coatings, Surf. Coat. Technol., 2010, 204(8), p 1163-1179

2. E. Bemporad, G. Bolelli, V. Cannillo, D. De Felicis, R. Gadow, A. Killinger, and L. Lusvarghi, Structural Characterisation of High Velocity Suspension Flame Sprayed (HVSFS) $\mathrm{TiO}_{2}$ Coatings, Surf. Coat. Technol., 2010, 204(23), p 3902-3910

3. N. Stiegler, D. Bellucci, G. Bolelli, V. Cannillo, R. Gadow, A. Killinger, L. Lusvarghi, and A. Sola, High-Velocity Suspension Flame Sprayed (HVSFS) Hydroxyapatite Coatings for Biomedical Applications, J. Therm. Spray Technol., 2012, 21(2), p 275287

4. J. Oberste-Berghaus, J.-G. Legoux, C. Moreau, F. Tarasi, and T. Chraska, Mechanical and Thermal Transport Properties of Suspension Thermal-Sprayed Alumina-Zirconia Composite Coatings, J. Therm. Spray Technol., 2008, 17(1), p 91-104

5. R. Gadow, A. Killinger, and J. Rauch, New Results in High Velocity Suspension Flame Spraying (HVSFS), Surf. Coat. Technol., 2008, 202(18), p 4329-4336

6. P. Fauchais, R. Etchart-Salas, V. Rat, J.F. Coudert, N. Caron, and K. Wittmann-Ténèze, Parameters Controlling Liquid Plasma Spraying: Solutions, Sols, or Suspensions, J. Therm. Spray Technol., 2008, 17(1), p 31-59

7. R. Rampon, F.-L. Toma, G. Bertrand, and C. Coddet, Liquid Plasma Sprayed Coatings of Yttria-Stabilized Zirconia for SOFC Electrolytes, J. Therm. Spray Technol., 2006, 15(4), p 682-688

8. C. Monterrubio-Badillo, H. Ageorges, T. Chartier, J.F. Coudert, and P. Fauchais, Preparation of $\mathrm{LaMnO}_{3}$ Perovskite Thin Films by Suspension Plasma Spraying for SOFC Cathodes, Surf. Coat. Technol., 2006, 200(12-13), p 3743-3756

9. A. Killinger, M. Kuhn, and R. Gadow, High-Velocity Suspension Flame Spraying (HVSFS). A New Approach for Spraying
Nanoparticles with Hypersonic Speed, Surf. Coat. Technol., 2006, 201, p 1922-1929

10. P. Fauchais, V. Rat, J.-F. Coudert, R. Etchart-Salas, and G. Montavon, Operating Parameters for Suspension and Solution Plasma-Spray Coatings, Surf. Coat. Technol., 2008, 202, p 43094317

11. G. Bertolissi, C. Chazelas, G. Bolelli, L. Lusvarghi, M. Vardelle, and A. Vardelle, Engineering the Microstructure of Solution Precursor Plasma-Sprayed Coatings, J. Therm. Spray Technol., 2012, 21(6), p 1148-1162

12. D. Chen, E.H. Jordan, and M. Gell, The Solution Precursor Plasma Spray Coatings Influence of Solvent Type, J. Plasma Chem. Plasma Process., 2010, 30(1), p 111-119

13. E. Dongmo, A. Killinger, M. Wenzelburger, and R. Gadow, Numerical Approach and Optimization of the Combustion and Injection Techniques in High Velocity Suspension Flame Spraying (HVSFS), Surf. Coat. Technol., 2009, 203(15), p 2139-2145

14. E. Dongmo, R. Gadow, A. Killinger, and M. Wenzelburger, Modeling of Combustion as well as Heat, Mass, and Momentum Transfer During Thermal Spraying by HVOF and HVSFS, J. Therm. Spray Technol., 2009, 18(5-6), p 896-908

15. S. Kamnis and S. Gu, Numerical Modeling of Propane Combustion in a High Velocity Oxygen-Fuel Thermal Spray Gun, Chem. Eng. Process., 2006, 45(4), p 246-253

16. S. Kamnis and S. Gu, 3-D Modeling of Kerosene-Fuelled HVOF Thermal Spray Gun, Chem. Eng. Sci., 2006, 61(16), p 5427-5439

17. E. Gozali, S. Kamnis, and S. Gu, Numerical Investigation of Combustion and Liquid Feedstock in High Velocity Suspension Flame Spraying Process, Surf. Coat. Technol., 2013, 228, p 176186

18. T. Furuhata, S. Tanno, T. Miura, Y. Ikeda, and T. Nakajima, Performance of Numerical Spray Combustion Simulation, Energy Convers. Manag., 1997, 38(10-13), p 1111-1122

19. E. Brinley, K.S. Babu, and S. Seal, The Solution Precursor Plasma Spray Processing of Nanomaterials, J. Miner. Met. Mater. Soc., 2007, 59(7), p 54-59

20. N. Zeoli, S. Gu, and S. Kamnis, Numerical Modeling of Metal Droplet Cooling and Solidification, Int. J. Heat Mass Transf., 2008, 51(15-16), p 4121-4131

21. B.E. Gelfand, Droplet Breakup Phenomena in Flows with Velocity Lag, Prog. Energy Combust. Sci., 1996, 22, p 201-265

22. S. Kamnis, S. Gu, T.J. Lu, and C. Chen, Computational Simulation of Thermally Sprayed WC-Co Powder, Comput. Mater. Sci., 2008, 43, p 1172-1182

23. N. Zeoli, S. Gu, and S. Kamnis, Numerical Simulation of In-Flight Particle Oxidation during Thermal Spraying, Comput. Chem. Eng., 2008, 32(7), p 1661-1668

24. R.S. Miller, K. Harstad, and J. Bellan, Evaluation of Equilibrium and Non-equilibrium Evaporation Models for Many Droplet Gas-Liquid Flow Simulations, Int. J. Multiph. Flow, 1998, 24(6), p 1025-1055

25. S.S. Sazhin, Advanced Models of Fuel Droplet Heating and Evaporation, Prog. Energy Combust. Sci., 2006, 32, p 162-214

26. W.E. Ranz and W.R. Marshall, Evaporation from Drops, Part I, Chem. Eng. Prog., 1952, 48, p 141-146

27. W.E. Ranz and W.R. Marshall, Evaporation from Drops, Part I, and Part II, Chem. Eng. Prog., 1952, 48, p 173-180

28. R.H. Perry and D.W. Green, Perry's Chemical Engineers' Handbook, 7th ed., McGraw-Hill, New York, 1997 